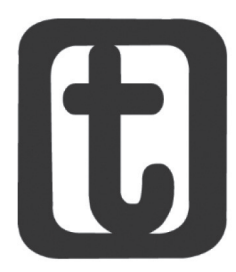

\title{
SUPEREXPLORAÇÃO DOS CORTADORES DE CANA NO AGRONEGÓCIO BRASILEIRO
}

\author{
OVEREXPLOITATION OF SUGARCANE CUTTERS \\ IN BRAZILIAN AGRIBUSINESS
}

\section{Claudilene da Costa Ramalho' Renata Couto Moreira ${ }^{2}$}

\section{RESUMO}

A teoria marxista da dependência de Ruy Mauro Marini é uma contribuição importante para compreender a economia política latino-americana em uma perspectiva crítica de análise. Neste artigo, as autoras buscam desvelar a partir dessa teoria contradições presentes na produção canavieira do Brasil. Concluem que, na atualidade, essas contradições vêm se acirrando devido à expansão do agronegócio, recolocando a atividade sucroalcooleira em destaque na pauta da exportação brasileira, assegurada pela superexploração de seus trabalhadores e pela perpetuação da condição de dependência do país na divisão internacional do trabalho. Nessa lógica de acumulação, o Estado exerce uma função fundamental, favorecendo a submissão de relações de superexploração dos cortadores de cana brasileiros.

Palavras-chave: Teoria marxista da dependência. Superexploração. Agroindústria canavieira.

\section{ABSTRACT}

The Ruy Mauro Marini marxist theory of dependence is an important contribution to understand the Latin American political economy in

1 Assistente Social. Mestranda do Programa de Pós-Graduação em Política Social da Universidade Federal do Espírito Santo. E-mail: kaucostar@hotmail.com.

2 Professora Adjunta do Departamento de Economia e do Programa de PósGraduação em Política Social da Universidade Federal do Espírito Santo. E-mail: renata.moreira@ufes.br. 
a critical perspective of analysis. In this paper, the authors attempt to reveal from this theory the contradictions in Brazilian sugarcane production. Conclude that, in actuality, these contradictions have been intensified due to the agribusiness expansion, replacing the sugarcane activity high on Brazilian export, ensured by overexploitation of its workers and by the perpetuation of the status of dependent country in the international division of labor. In this accumulation logic, the State exercises a fundamental function, promoting the submission of overexploitation relations of Brazilian sugarcane cutters.

Keywords: Marxist theory of dependence. Overexploitation. Sugarcane agroindustry.

Submetido em 14/09/2013

Aceito em 07/01/2014

\section{INTRODUÇÃO}

A produção agrícola no Brasil, historicamente, esteve atrelada aos interesses do grande capital legitimado pelo Estado, definindo qual a atividade produtiva, que mão de obra seria mais interessante, a forma como deveria ser dividida e usada a terra, bem como para que e quem seria direcionada a produção do Brasil. Nesse sentido, a produção canavieira está relacionada diretamente aos interesses hegemônicos do grande capital internacional, interiorizados pelos países latino-americanos, influenciando a formação social e econômica brasileira. A cana-de-açúcar, trazida da Índia, foi imposta na sua exploração comercial ainda no período colonial, conforme a necessidade dos países europeus (STEDILE, 2005).

Fernandes (1973) ressalta que a incorporação da América Latina no capitalismo ocorreu de forma dependente econômica, cultural e politicamente dos países capitalistas hegemônicos. A produção canavieira e o incentivo dado por Portugal à implantação dos engenhos no Brasil não foram uma escolha aleatória, mas tinham por objetivo atender aos interesses da acumulação capitalista comercial dos países hegemônicos na divisão internacional do trabalho.

De acordo com Mancio et al. (2012), a partir do século XX, passa-se a identificar um processo de reprimarização da economia que se expressa na primazia dada à exportação de commodities, de produtos minerais e agrícolas, conforme financiamento 
do Estado. A produção canavieira tem um papel expressivo nesse processo e encontra-se embasada na expansão do agronegócio e na utilização da superexploração do trabalho, como forma de compensar a transferência de valor para os países centrais.

Dessa forma, a compreensão da teoria marxista da dependência possibilita perceber nuances da questão agrária³ brasileira, mais precisamente o papel do setor sucroalcooleiro no processo de acumulação do capital e na reafirmação da superexploração e da dependência latino-americana, sendo este o objetivo geral do estudo. Para tanto, pretende-se analisar o papel que o Brasil exerce na divisão internacional do trabalho, sob a hipótese de ser este subordinado aos interesses hegemônicos dos países centrais numa relação dialética de dependência e exploração, desenvolvimento e subdesenvolvimento, tendo como espaço privilegiado de análise as relações de trabalho na produção canavieira brasileira. Este artigo está organizado em três seções, além desta breve introdução. Em um primeiro momento, aprofunda-se o estudo das categorias da teoria da dependência em Marini (2005), essenciais para a análise. Em segundo, busca-se debater o desenvolvimento da produção canavieira em uma estratégia deliberada pelo Estado brasileiro, com primazia ao agronegócio. Em um terceiro momento, é abordada a expansão da agroindústria canavieira, ressaltando o aprofundamento da dependência com o agronegócio e a superexploração do trabalho intrínseco à sua lógica.

\section{A DEPENDÊNCIA EM MARINI: DAS TROCAS DESIGUAIS À SUPEREXPLORAÇÃO}

A história do capitalismo na América Latina, especificamente no Brasil, carrega algumas especificidades em relação à

\footnotetext{
3 Kaustsky (1968), buscando analisar o desenvolvimento da agricultura moderna na Prússia, ressalta que "a questão agrária, segundo o método de Marx, não se deve equacionar apenas o problema de saber se a pequena exploração tem ou não futuro na agricultura. Deve-se, ao contrário, pesquisar todas as transformações experimentadas por esta última no decurso do regime de produção capitalista. Deve-se pesquisar se e como o capital se apodera da agricultura, revolucionando-a, subvertendo as antigas formas de produção e de propriedade, criando a necessidade de novas formas" (KAUSTSKY, 1968, p. 57). Isso levanta, então, as contradições no desenvolvimento do capitalismo na agricultura, que conformarão, em cada momento histórico e em cada região, a questão agrária.
} 
forma pura do modo de produção capitalista. Assim, é importante entendermos que o capitalismo é um sistema em conjunto e o seu funcionamento é dado cada vez mais de forma global e integrada (MARINI, 2005). Inicialmente, foi atribuída à América Latina a função de contribuir com o "fluxo de mercadorias e com a expansão dos meios de pagamento" (MARINI, 2005, p. 140), permitindo, assim, que se desenvolvesse na Europa o capitalismo comercial e usurário e favorecendo a criação da grande indústria.

Para Marini (2005), os países latino-americanos estruturam-se após a independência política em torno dos interesses ingleses de expansão dos mercados para a exportação de suas mercadorias e de capitais. Essa estrutura de submissão aos interesses do mercado mundial permanece até a atualidade, sendo expressa pela subordinação dos países latino-americanos a uma relação internacional de dependência econômica (GALEANO, 2010). Portanto, a independência política perpetua a dependência econômica e cultural aos grandes centros capitalistas, pois, como será evidenciado, não é possível suprimir as relações de produção que estão entrelaçadas a essa dependência (MARINI, 2005). Ou seja, é a divisão internacional do trabalho que define a importância das atividades produtivas, bem como, no caso da produção canavieira, se esta continuará ou não sendo central para os interesses externos, causando avanços e recuos no setor.

Assim, restaram, nesse processo, os países dependentes, com a função de oferecer produtos da agropecuária e de ofertar matéria-prima para os países centrais. Foi um sucesso a forma como a América Latina cumpriu sua primeira função, pois possibilitou que os países centrais se especializassem na atividade industrial e que a sua população se liberasse em grande medida, ficando à disposição nas cidades e formando assim a classe operária europeia. Já a segunda função (ofertar matéria-prima) é, para Marini (2005), a relação mais duradoura entre América Latina e países centrais, permanecendo mesmo depois de aquela ter alcançado um novo estágio na divisão internacional do trabalho. Dessa forma, a relevância da análise desse autor cresce conforme se aprofunda o desenvolvimento do capitalismo. 
Além de facilitar o crescimento quantitativo do capitalismo, essa nova configuração econômica da América Latina contribui para uma mudança qualitativa na exploração do trabalho. A produção nos países centrais deixa de ser fundada na expansão da exploração via mais-valia absoluta (aumento da jornada de trabaIho) e passa a incorporar também uma massa de mais-valia relativa (diminuição do tempo de trabalho socialmente necessário para a reprodução da força de trabalho). Em contrapartida, na América Latina, aumenta-se o nível de exploração dos seus trabalhadores, o que se configura, de acordo com Marini (2005), num processo de acumulação baseado na superexploração do trabalho. A desvalorização da força de trabalho na Europa, portanto, teve a contribuição da América Latina, ao ofertar, de maneira farta e barata, alimentos para a classe trabalhadora europeia. Na medida em que o preço da cesta de bens dos trabalhadores é diminuído, reduz-se também a relação entre o tempo de trabalho necessário e o tempo de trabalho excedente. Com o aumento da capacidade produtiva do trabalho, passa-se a requerer uma quantidade maior de matérias-primas, cumprindo à América Latina, também, a função de ofertar matéria-prima farta e barata aos países centrais.

Para Marini (2005), as diferentes composições orgânicas dos setores que se distribuem de forma heterogênea entre os países na divisão internacional do trabalho levam a um processo de trocas desiguais, o qual transfere valores produzidos nos países de menor composição média para os de maior composição, na dissimulação dos valores em preços de produção. Na concorrência entre os capitais, com sua mobilização e imobilização nos distintos ramos produtivos, haverá uma tendência, em longo prazo, de equalização das taxas de lucro, que se dará via transferências de valor.

Nessa relação entre países, a saída que as economias dependentes encontram é via ganhos de escala e superexploração do trabalho e dos recursos naturais, como compensação das desigualdades nas trocas. Com isso, a América Latina exporta matérias-primas e alimentos produzidos em setores com relativamente baixa composição orgânica do capital para os países centrais e importa deles manufaturas industrializadas em setores de elevadas composições. Esse é o segredo das trocas desiguais, visto 
que nos países latino-americanos são produzidas mercadorias que necessariamente serão vendidas por preços abaixo do seu valor no mecanismo de equalização tendencial das taxas de lucro. Esse mais valor produzido será apropriado pelos países centrais, via maiores preços relativos, que obterão associados aos seus produtos, aparecendo acima do valor que possuem. As classes dominantes da América Latina resolveram essa contradição com a incorporação do latifúndio à agricultura e a superexploração de sua força de trabalho.

Essa contradição no desenvolvimento do capitalismo na América Latina faz com que o trabalhador seja remunerado abaixo do valor da sua força de trabalho, ficando limitado na quantidade de bens necessários para a reprodução da sua subsistência, causando o seu atrofiamento. Nesse sentido, a categoria superexploração merece sua centralidade nas análises sobre os países latino-americanos. Esse quadro está relacionado, conforme Marini (2005), com as atividades que esses países desempenham na mineração e na agricultura, já que não precisam, como ocorre na indústria moderna, aumentar o capital constante 4 e as capacidades produtivas para elevar os lucros. A ampliação da lucratividade ocorre fundamentalmente na expropriação da força de trabalho, à qual não se garante nem mesmo o pagamento de seu próprio valor, quanto mais dos valores que ela produz. Resulta em um esgotamento prematuro do trabalhador, já que não ocorre a reposição de seu desgaste, possibilitando transferências da mais-valia produzida na América Latina para os países centrais.

Essa superexploração do trabalho, que causa o desgaste e a morte de muitos trabalhadores, não se torna um empecilho para o capitalismo devido à grande disponibilidade de mão de obra excedente e à configuração estabelecida na divisão internacional do trabalho. As mercadorias produzidas nos países dependentes não são para o consumo de seus próprios trabalhadores, mas estão disponíveis no mercado mundial, independentemente do desenvolvimento de seus mercados internos. Esse descolamento das esferas de produção e consumo cria espaços para ampliar o

4 De acordo Marx (1996), no cap. XXIII de O Capital, o capital constante expressa o valor dos meios de produção (matérias-primas e meios auxiliares). 
processo de superexploração dos trabalhadores latino-americanos, como discutem Traspadini et al. (2005).

Para Mancio et al. (2012), nessa relação dialética, em que o subdesenvolvimento é resultado do desenvolvimento, há um aprofundamento da dependência da América Latina, pois cada vez mais ocorre espoliação das riquezas, que resulta em transferência de valor dos países subdesenvolvidos para os desenvolvidos. De acordo com Marini (2005), nos países dependentes, como a maior parte da produção é destinada à exportação, ocorre a separação das esferas de produção e circulação, sendo que esta se divide ainda em duas esferas: a do consumo dos capitalistas e a dos trabalhadores, garantindo a importação dos manufaturados dos países centrais, o que completa a relação de dependência e superexploração. Isso acontece principalmente porque a América Latina é incorporada na divisão internacional do trabalho não para atender a suas exigências, mas para dar conta de uma demanda externa já existente.

Mesmo incorporando uma maior composição orgânica do capital no período de industrialização da América Latina, em que se aumentou a produtividade no trabalho por meio do incremento de modernização técnica organizacional, permanece inalterada a base da superexploração do trabalho. Marini (2005) ressalta que as configurações assumidas na economia internacional sob a égide estadunidense, a partir de 1950, são responsáveis por esse modelo de industrialização dos países dependentes financiado pelo capital estrangeiro. Essa importação de capital estrangeiro é resultado da concentração de capitais nos países centrais, os quais impõem a necessidade de suas grandes corporações imperialistas investirem, devido à maior lucratividade, nos setores industriais das periferias. Essa maior lucratividade, em grande medida, é proporcionada pela superexploração do trabaIho, favorecida pelo enorme exército de reserva, e pela abundância de recursos naturais disponíveis.

No entanto, a importação de tecnologias, embora possibilite elevar a produtividade no trabalho, não suprime a superexploração que se manifesta, dentre várias formas, nas condições degradantes de trabalho e nas mortes prematuras por exaustão. 
O trabalhador continua a ser remunerado abaixo do valor de sua força de trabalho e os setores agrícola e extrativo mineral continuam a ter papel predominante na pauta de exportações desses países e na acumulação do capital em escala mundial. Assim, na atualidade, percebe-se dentro da perspectiva da divisão internacional do trabalho, de acordo com Mancio et al. (2012), que ocorre o aprofundamento da dependência dos países da América Latina, abortando a diversificação e industrialização dos anos 1950 e sendo imposta uma forte especialização na produção de commodities e bens primários em geral. O capital estrangeiro, responsável por comandar o financiamento, a comercialização e a produção nos países dependentes, alcança seus objetivos de se apropriar por meio de operações financeiras, remessas de lucros e dividendos, de uma parte cada vez maior da mais-valia produzida. Delgado (2010) corrobora esse mecanismo e conclui destacando como resultado do processo o constrangimento do crescimento econômico em padrões de subdesenvolvimento.

Dessa forma, a condição de dependência da América Latina não só permanece, mas também vem sendo aprofundada, como podemos perceber na agricultura e na produção canavieira do Brasil. O setor sucroalcooleiro no Brasil é um dos que vêm tendo um crescimento de investimento público e privado com fortes influências sobre o processo de reprimarização por meio da expansão do agronegócio 5 . Esse setor tem o papel de colocar na atualidade o país na posição de maior exportador de açúcar do

5 Para Stedile (2010), pode-se dizer que o capital e seus proprietários-capitalistas, representados por grandes proprietários de terra, bancos e empresas nacionais e transnacionais, estão aplicando em todo mundo o chamado modelo de produção do agronegócio (agribusiness), que se caracteriza sucintamente por: organizar a produção agrícola na forma de monocultivo (um só produto) em escalas de áreas cada vez maiores voltadas para a exportação de commodities e usar de modo intensivo máquinas agrícolas e insumos químicos, em escalas cada vez maiores, expulsando a mão de obra do campo. Nossa compreensão desse termo articula, além da dimensão econômica e organizacional, relações políticas de coordenação do processo produtivo, como explica Christoffoli (2012, p. 74): “[...] designa, numa versão crítica, a articulação técnica, política e econômica dos elos representados pelos segmentos produtivos de insumos para a agricultura, do mercado de trabalho e de produção agrícola, bem como as etapas de armazenagem, processamento e distribuição dos produtos agrícolas, agora articulados pelo capital financeiro em escala internacional, numa dinâmica de abertura de mercados e globalização neoliberal da economia". 
mundo e com um grande potencial na produção de biocombustíveis, como será apresentado na análise a seguir.

\section{A MODERNIZAÇÃO DA AGROINDÚSTRIA CANAVIEIRA E O PAPEL DO ESTADO}

As mudanças na dinâmica capitalista causaram modificações na agricultura brasileira, impulsionadas pelo processo de modernização ${ }^{6}$. Na agroindústria canavieira, a modernização foi favorecida pelo surgimento do derivado da cana-de-açúcar, o etanol. Esse produto teve seus primeiros avanços em pesquisa a partir de 1920, estando relacionado com a busca de alternativa para o setor devido à crise no mercado de açúcar (FREDO et al., 2012). O Estado brasileiro foi um dos principais indutores do processo de modernização da agricultura e tem sido historicamente um aliado do setor canavieiro (PITTA, 2011). O marco regulatório 19.197 de 1931 do governo federal garantiu a criação de mercado para o etanol, já que o combustível dos carros passou a ter obrigatoriedade de $5 \%$ de álcool na gasolina. Nesse período, o Brasil não produzia petróleo e dependia totalmente da importação da gasolina (FREDO et al., 2012)

Além disso, foi criado em 1933 o Instituto do Açúcar e Álcool (IAA) 7 , que teve como função controlar e normatizar a produção desses produtos em todo o país, como também participar da produção de álcool anidro, com a instalação e o fomento das destilarias centrais (ALVES, 1991). Os incentivos financeiros e administrativos do IAA garantiram que a agroindústria canavieira deixasse

6 De acordo com Alentejano ( 2012, p. 478), o processo de modernização da agricultura brasileira foi concebido e planejado como contraponto às propostas de Reforma Agrária gestadas no âmbito da esquerda brasileira ao longo dos anos de 1950-1960. Segundo os defensores da modernização, seria possível desenvolver plenamente a capacidade produtiva da agricultura brasileira sem a distribuição de terras, numa visão das suas funções clássicas apenas para o fornecimento de alimentos, matérias-primas e mão de obra para o processo de industrialização e urbanização crescentes, contraditoriamente ao que defendiam os partidários da Reforma Agrária, que levavam em conta as questões sociais advindas da desigualdade como limite ao próprio desenvolvimento econômico.

7 O IAA é o programa de Racionalização da Agroindústria Canavieira que modificou substantivamente a política de intervenção no setor, objetivando reformular a política açucareira, aumentando a produtividade do setor e reduzindo os seus custos. O recurso utilizado era o estímulo às unidades industriais dotadas de maior capacidade (HEREDIA, 2008, p. 58). 
de ter prejuízo e possibilitaram o desenvolvimento do mercado interno e a transferência do eixo de produção do Nordeste para o Centro-sul. Favoreceram ainda a ampliação da produção de álcool e açúcar com o financiamento para a construção de destilarias e usinas (SZMRECSÁNYI et al., 1991).

Durante a Segunda Guerra Mundial (1939-1945), ocorreu uma diminuição do volume de exportações no Brasil, tanto no açúcar como nos demais produtos. Iniciou-se, assim, o processo de substituição de importações e o desenvolvimento do parque industrial nacional financiado pelo capital estrangeiro. Nesse contexto internacional de crise do capital, relacionada também à crise do petróleo, ocorreu o restabelecimento da produção açucareira voltada para exportação. Desse modo, "com a escassez dos derivados do petróleo, houve uma valorização da produção do álcool, especialmente o anidro, cuja mistura à gasolina, ainda durante a Segunda Guerra, passou de 5\% para 20\% em 1941" (SANTOS, 2009, p. 112). De acordo com lamamoto (2006), o processo de transição e expansão da agroindústria canavieira para o mercado interno foi norteado pelo investimento das empresas estatais, da burguesia nacional e do capital estrangeiro.

A partir de 1959, o IAA constituiu um grupo técnico para elaborar propostas que visassem aumentar a produção. No entanto, como no período anterior o setor estava passando uma crise de superprodução, o cenário não era favorável à implantação de medidas que aumentassem a produtividade. Esse contexto foi alterado devido à revolução cubana de 1959, com o rompimento entre Cuba e Estados Unidos, ampliando o mercado para a exportação do açúcar brasileiro (SZMRECSÁNYI et al., 1991).

Para Delgado (2001), o modelo de desenvolvimento da agricultura, implantado pós década de 1960, intitulado pelo autor de "modernização conservadora", nasceu com a derrota da proposta pautada na Reforma Agrária. Passou a responder aos intensos movimentos de urbanização e industrialização. A mudança da base técnica da agricultura deu-se através da criação, por parte do Estado, do Sistema Nacional de Crédito Rural (SNCR) para financiar o processo de modernização da agricultura. 
Em 1975, em virtude da preocupação com a superprodução do açúcar, tendo como justificativa oficial aliviar a balança comercial, devido à elevação do preço do petróleo, foi criado pelo IAA o Programa Nacional do Álcool (PNA), conhecido como Proálcool ${ }^{8}$. Esse programa representou uma resposta do Estado à derrocada do setor, já que entre 1969 e 1974 o açúcar brasileiro viveu seu período de ouro no mercado internacional, passando, depois, por uma crise de superprodução (SANT'ANA, 2012). Dessa forma, o Estado tornou-se responsável pelo financiamento de destilarias de álcool anidro, facilitando ainda a importação de máquinas e equipamentos e colocando o Centro-sul na posição de maior produtor de açúcar e álcool do Brasil. A expansão canavieira, tanto para estados do Centro-sul, dentre eles São Paulo, Rio de Janeiro e Minas Gerais, quanto para regiões sem grande tradição da cultura canavieira, dentre eles Paraná, Goiás e Mato Grosso, representou a diminuição da importância dos produtores nordestinos (SZMRECSÁNYI et al., 1991).

Conforme Alves (1991), os incentivos estatais foram voltados principalmente à produção de álcool e contribuíram com mudanças em todas as fases de produção. O acesso ao SNCR tinha como condicionalidade, de acordo com Fredo et al. (2012), um pacote tecnológico que incorporava o uso de insumos químicos e implementos agrícolas, objetivando a melhoria e padronização do sistema de produção. Foi voltado também para mudanças nas relações de trabalho, com o amplo estabelecimento do trabalho assalariado, marcando a integração entre a agricultura/indústria.

Como resultado do aumento dos preços do petróleo em 1979, ocorre o lançamento da segunda etapa do Proálcool. Nessa fase, é proposta a produção de álcool hidratado, tornando-o um carburante direto e não apenas um aditivo à gasolina, como o álcool anidro (SZMRECSÁNYI et al., 1991).

8 De acordo com lamamoto (2006), o Proálcool é o Programa Nacional do Álcool, que propõe a substituição da gasolina por etanol, estreitamente articulada à crise energética, devido às altas do preço do petróleo em 1973 e 1974. Além de assegurar um mercado seguro e crescente para o álcool e abrir campo ao mercado internacional do açúcar, permite não somente a expansão da cultura canavieira como também a sustentação econômica do setor. Na realidade, o Proálcool foi desde o início um programa para os grandes usineiros. 
Em primeiro momento, o governo criou um mercado consumidor de carros movidos a álcool, por meio de incentivos fiscais a montadoras de carros equipados com motor movido a álcool. Em segundo, fixou o preço do álcool hidratado, 65\% a menos que a gasolina, embora o custo da gasolina fosse menor. Em terceiro, promoveu o favorecimento das linhas de créditos para a produção de cana destinada às destilarias de álcool mais do que para produção açucareira, mesmo não ocorrendo uma diminuição absoluta nesta, devido à expansão canavieira que estava acontecendo no período (SZMRECSÁNYI et al., 1991).

De acordo com dados apresentados por Alves (1991), a produtividade por hectare saltou de 49,2 toneladas, em 1968/1969, para a média de 60 toneladas pós-década de 1980. O processo fortaleceu a hegemonia do capital sobre o trabalho, principalmente sob o julgo do agronegócio, e levou à intensificação do trabalho e à redução dos salários dos cortadores de cana por meio de estratégias como o pagamento por produção.

Com a crise dos anos 1980 e a transição para o padrão liberalizante nos anos 1990, os instrumentos políticos de intervenção do Estado no setor rural sofreram um desmonte (DELGADO, 2001). Durante o segundo governo de Fernando Henrique Cardoso (1998 a 2002), ocorre o relançamento do agronegócio como estratégica econômica e política para gerar saldos positivos na balança comercial via exportação de produtos primários, porém sob outras bases de sustentação da associação entre o grande capital agroindustrial e o latifúndio, em uma dinâmica ditada pelo capital financeiro, como esclarece Delgado (2010).

Os instrumentos públicos reaparecem em investimentos na infraestrutura territorial, pesquisa agropecuária, regulação frouxa do mercado de terras e alterações na política cambial e de crédito rural. As exportações retomam uma trajetória ascendente nos anos 2000. No entanto, a especialização em meia dúzia de commodities em rápida expansão, em que o açúcar e o álcool têm papel de destaque, insere um dilema na conta-corrente do país, impondo sérias restrições ao desenvolvimento e às soluções de desequilíbrio externo. A primazia dada à exportação de produtos básicos, que crescem de $25 \%$ da pauta, em 2000, para $45 \%$, 
em 2010, teve como efeito a perda de espaço para os manufaturados, caindo de $56 \%$ das exportações para $43,4 \%$, no mesmo período, refletindo o retrocesso na industrialização da economia (DELGADO, 2010).

Dessa forma, a acumulação de capital pela renda fundiária e pelas vantagens comparativas posterga mais uma vez um enfrentamento dos problemas sociais associados à superexploração do trabalho e à questão agrária brasileira.

\section{EXPANSÃO DO AGRONEGÓCIO SUCROALCOOLEIRO E SUPEREXPLORAÇÃO DOS CORTADORES DE CANA}

O setor canavieiro é caracterizado por fatores que marcaram a expansão e a concentração de terras e capitais nas mãos das transnacionais e oligarquias, levando ao agravamento da questão agrária, segundo Mancio et al. (2012). A prevalência desse modelo na produção canavieira representa "o aumento da produção da cana-de-açúcar no Brasil em milhões de toneladas, tendo em 2007/2008, produzido 486. Está previsto que em 2015/2016, passe para 829 e em 2020/2021, para 1.038 milhões de toneladas" (NEVES et al., 2010, p. 19).

Entre 2008 e 2012, estima-se um investimento de US\$ 23 bilhões em 76 projetos de construção de novas usinas de etanol e açúcar e mais de US\$10 bilhões na produção do açúcar, conforme Neves et al. (2010). Para a Rede Social de Justiça e Direitos Humanos e Comissão Pastoral da Terra (2008), o Brasil deve construir de duas a três usinas por mês até 2013, o que corresponde a 336 usinas construídas em 2008 e 409 (ou 598, com os projetos já em andamento) previstas para o final da safra 2012/2013. A previsão é de que, até 2025, o país tenha 615 usinas de etanol, trazendo a expansão da monocultura da cana-de-açúcar, destruição dos recursos naturais, expropriação de famílias camponesas e afetando consequentemente a produção de alimentos.

Os incentivos do Estado ao setor sucroalcooleiro ocorrem por meio da aprovação de legislações, incentivos fiscais, crédito a juros subsidiados e financiamentos. De acordo com o Departamento Intersindical de Estatísticas e Estudos Socioeconômicos (DIEESE, 2007), só para 2012, foi previsto que o 
investimento do Banco Nacional de Desenvolvimento Econômico e Social (BNDES), para esse setor, chegasse a US\$12 bilhões de dólares. A esse respeito, Marini (2005, p. 179) afirma que "assiste-se em toda América Latina à ressurreição do modelo da velha economia exportadora", financiada por recursos públicos que poderiam ser destinados a políticas que beneficiassem amplos setores sociais, mas são repassados para ampliar a concentração do grande capital.

Esses fatores ajudam a intensificar a nossa condição de economia dependente e causam inúmeros impactos negativos tanto para o trabalhador cortador de cana como para a população em geral. Alves (1991) assevera que, para manterem seus empregos, os cortadores foram obrigados a aumentar em $100 \%$ a produtividade do seu trabalho, passando de 6 toneladas/homem/dia, na década de 1980, para 12 toneladas, na década de 1990. Esse aumento foi acompanhado pela retomada da expressividade da produção canavieira na pauta da exportação brasileira. Dessa forma, 70\% do açúcar produzido no Brasil é exportado para mais de 100 países, sendo na atualidade o maior exportador de açúcar e responsável por $45 \%$ da produção do etanol em nível mundial, de acordo com a Rede Social de Justiça e Direitos Humanos (2011).

Conforme os dados do DIEESE (2007), no ano de 2010, a exportação de açúcar em milhões de toneladas foi de 18,1; para 2015, a previsão é de 20,5. Em relação ao etanol, as exportações em bilhões de litros foram de 4,3, em 2010, com previsão de 6,9, em 2015. Nesse sentido, aposta-se na atualidade da teoria marxista da dependência para explicar a realidade brasileira, por entender que há uma prevalência das trocas desiguais nas relações internacionais nas quais o setor está inserido. Essas relações se dão com perdas para o país, as quais são parcialmente compensadas por meio da superexploração do trabalho. Esse fenômeno é evidenciado pela análise do DIESSE (2007), que mostra que no corte de cana, apesar do aumento na formalização do emprego em São Paulo, chegando a 90\%, a produtividade cresceu $236,8 \%$, enquanto que o salário caiu 5,5\%, chegando, em 2006, à morte de 450 trabalhadores na atividade. De acordo com Silva (2011), há no setor a prevalência da utilização da mão de obra migrante temporária de regiões empobrecidas, o que facilita a maior exploração do 
trabalhador. Esses fatores favorecem o esgotamento prematuro do trabalhador, já que, conforme Silva (2005), com o aumento de produtividade dos cortadores de cana, a vida útil desses trabalhadores é menor que a dos escravos africanos do século XIX.

A resposta do governo à crise atual está relacionada ao investimento estimulado via cortes tributários e crédito destinado ao complexo automobilístico-petroleiro na produção de agrocombustíveis, principalmente na produção de cana e milho para o etanol. Esse modelo ainda intensifica a mecanização, o uso de agrotóxico e a expropriação camponesa, agravando ainda mais a questão social e ambiental que gera e propaga, conforme ressalta Stedile (2010). Representa o controle do grande capital internacional sobre as tecnologias e patentes, as imensas áreas de terras brasileiras e a produção por meio de fusões e aquisições de empresas nacionais. Por mais que o setor venha aumentando a composição orgânica do capital com o avanço das forças produtivas, estabelece os ganhos de produtividade com um aprofundamento do processo de superexploração do trabalho e da condição de dependência, favorecidos pela consolidação do modelo de desenvolvimento agrário e agrícola caracterizado pelo agronegócio.

Retorna-se à questão das duas esferas de consumo interno, a dos trabalhadores e a dos capitalistas, que estão desconectadas, abrindo espaço para a superexploração. Para Carcanholo (2011), a superexploração não coloca impedimento à acumulação interna do capital com a restrição do consumo da força de trabalho, porque a acumulação interna é dependente do mercado externo e/ou voltada às camadas média e alta da população brasileira. Como resultado, o consumo da força de trabalho é afetado pelo aumento dos preços dos alimentos, já que as áreas que seriam direcionadas para o seu cultivo concorrem com o monocultivo de cana. Este, voltado para exportação ou para a produção de bicombustível, favorece apenas a concentração de lucros no ramo automobilístico, direcionando-se aos postos de combustíveis, ao agronegócio canavieiro e ao barateamento do consumo interno das classes alta e média, que passam a adquirir ou a trocar seu automóvel movido à gasolina para flex fuel. 
Para Martins (2011), a produção canavieira e de etanol como energia verde traz o receituário imposto aos países dependentes. Sendo assim, a energia verde do etanol, em "combate" ao aquecimento global, carrega as contradições advindas da dominação do capital internacional sobre o trabalho e a perpetuação do subdesenvolvimento e dos próprios condicionantes do aquecimento global. Nessa perspectiva de análise, a produção do setor para exportação permanece, de um lado, estabelecendo a dependência e, de outro, aprofundando-a, com a aquisição e fusão de usinas pelo capital estrangeiro, passando o centro de decisões cada vez mais para o exterior. Isso reforça a possibilidade de manter os trabalhadores migrantes do corte da cana em condições de superexploração, completando o ciclo de acumulação ampliada do capital.

\section{PRINCIPAIS CONCLUSÕES}

Analisando a economia da cana-de-açúcar desde o engenho ao agronegócio, percebemos que a teoria da dependência permanece atual e necessária para compreendermos a lógica da acumulação do capital internacional, o qual direciona as prioridades para o desenvolvimento capitalista dos países do sul. Esse desenvolvimento é impossível de ocorrer, já que nossa condição de subdesenvolvidos é o que sustenta historicamente a posição dos países centrais como desenvolvidos. Assim, a resposta da periferia em busca do sonho do desenvolvimento historicamente tem sido baseada rigorosamente na superexploração de seus trabalhadores.

Nessa perspectiva, o agronegócio da cana-de-açúcar, por meio do Proálcool, deve ser compreendido como um programa de legalização e incentivos do Estado em favor do grande capital internacional. Cabe então ressaltar que, nesse sentido, a energia "limpa" do etanol, principal meta do governo atual, não está somente carregada de impurezas, provenientes do extermínio de trabalhadores nos canaviais, mas também da condição latino-americana de dependência, o que compromete a autonomia da nação, sua soberania alimentar e nutricional. Aprofundar esse modelo representa um caminho inverso ao que poderia ser uma forma de romper com essa lógica de superexploração e submissão 
do trabalho pelo capital e de supressão das relações de dominação presentes no plano internacional e nacional.

\section{REFERÊNCIAS}

ALENTENJANO, P. Modernização da agricultura. In: CALDART, S. R. et al. Dicionário de educação do campo. São Paulo: Escola Politécnica de Saúde Joaquim Venâncio; Expressão Popular, 2012.

ALVES, F. Modernização da agricultura e sindicalismo: lutas dos trabalhadores assalariados rurais na região de Ribeirão Preto.1991. Tese (Doutorado) - Instituto de Economia, Universidade Estadual de Campinas, Campinas, 1991. Disponível em: <http://www.bibliotecadigital.unicamp.br/document/?code=vtlso00035593>. Acesso em: 10 jan. 2013

CARCANHOLO, R. Capital: essência e aparência. São Paulo: Expressão popular, 2011.

CHRISTOFFOLI, P. I. Agroindústria. In: CALDART, S. R. et al. Dicionário de educação do campo. São Paulo: Escola Politécnica de Saúde Joaquim Venâncio; Expressão Popular, 2012.

CONAB. 2008. Acompanhamento da safra brasileira: cana-de-açúcar safra 2007/2008. Disponível em: <http://www.conab.gov. br/conabweb/download/safra/3lev-cana.pdf> Acesso em: 21 jun. 2012.

CONAB. Acompanhamento da safra brasileira: cana-de-açúcar safra 2012/2013. Brasília, 2012. Disponível em: <http://www.conab. gov.br/OlalaCMS/uploads/arquivos/12_04_10_09_19_04_boletim_de_cana.pdf>. Acesso em: 21 jun. 2012.

DELGADO, G. C. Expansão e modernização do setor agropecuário no pós-guerra: um estudo da reflexão agrária. Revista Estudos Avançados, v. 15, n. 43, p. 157-172, 2001.

DELGADO, G. C. O setor de subsistência na economia e na sociedade brasileira: gênese histórica, reprodução e configuração contemporânea. In: RAMALHO, J. P. et al. (Org.). Desenvolvimento, 
subsistência e trabalho informal no Brasil. São Paulo: Cortez; Centro Alceu Amoroso Lima para a Liberdade - CAALL, 2004.

DELGADO, G. C. Especialização primária como limite ao desenvolvimento. Desenvolvimento em Debate, v. 1, n. 2, p. 111-125, jan./ ago. 2010. Disponível em: <http://desenvolvimentoemdebate. ie.ufrj.br/pdf/dd_guilherme.pdf>. Acesso em: 10 abr. 2013.

DIEESE. Desempenho do setor sucroalcooleiro brasileiro e os trabalhadores. Relatório de prestação de contas do Encontro Nacional do Setor Sucroalcooleiro, 2007. Disponível em: <http:// www.dieese.org.br/projetos/BNDES/relatorioEncontroSucroalcooleiro.pdf >. Acesso em: 12 jul. 2012.

DIEESE. Desempenho do setor sucroalcooleiro brasileiro e os trabalhadores. Estudos e pesquisa. Ano 3, n. 3, 2007. Disponível em: <http://www.diesse.org.br/esp/estpesq30 setorSucroalcooleiro. pdf>. Acesso em: 11 maio 2012.

FERNANDES, F. Padrões de dominação externa na América Latina. In: Capitalismo dependente e classes sociais na América Latina. Rio de Janeiro: Zahar, 1973.

FREDO, C. E. et al. Tecnologia x Emprego no Setor Sucroalcooleiro de São Paulo. Rev. de Economia Agrícola, São Paulo, v. 59, n. 1, p. 1-116, jan./jun. 2012. Disponível em: ftp://ftp.sp.gov.br/ftpiea/ rea/2012/rea1-1-12.pdf>. Acesso em: 18 out. 2012.

GALEANO, E. H. As veias abertas da América Latina. Porto Alegre: L\&PM, 2010. 400p.

HEREDIA, B. M. A. de. O campesinato e a plantation. A história e os mecanismos de um processo de expropriação. In: DELMA, P. N. et al. (Org.). Processos de constituição e reprodução do campesinato no Brasil. volume: Formas tuteladas de condição camponesa. São Paulo: Editora da UNESP; Brasília: Núcleo de Estudos Agrários e Desenvolvimento Rural, 2008.

IAMAMOTO, M. V. Trabalho e indivíduo social. São Paulo: Cortez, 2006. 
KAUTSKY, K. A questão agrária. São Paulo: Nova Cultural, 1968.

MANCIO, D. et al. A dependência latino-americana e a reprimarização do continente. In: XVII ENCONTRO NACIONAL DE ECONOMIA POLÍTICA, 2012, Rio de Janeiro. Anais... Rio de Janeiro: UFRJ, 2012. p. 1-25.

MARTINS, H. A ameaça à soberania nacional pela expansão do complexo agroquímico a partir da cana-de-açúcar e do etanol. In: MARTINS, H.; CALAZANS, M.; STEDILE J. P.; HOUTART, F. Questão agrária contemporânea e os movimentos camponeses da América Latina. Coletânea de textos da Escola Nacional Florestan Fernandes, n. 9, São Paulo, p.5-19, ago. 2011. Disponível em: <http:// webcache.googleusercontent.com/search?q=cache: $6 \mathrm{dcjSeVI} 2 \mathrm{Y} 8$ J:files.crbzonadamata.webnode.com.br/200000182f236800065/ Colet\%25C3\%25A2nea\%2520n\%25C2\%25BA\%25209\%2520\%2520site $\% 2520 \mathrm{crb} \cdot \mathrm{pdf}+\& \mathrm{~cd}=1 \& \mathrm{hl}=\mathrm{pt}-\mathrm{BR} \& \mathrm{ct}=\mathrm{clnk} \& \mathrm{gl}=\mathrm{br}>$. Acesso em: 04 fev. 2013.

MARX, K. O capital: crítica da economia política - o processo de produção do capital. Tradução de Regis Barbosa e Flávio R. Kothe. Livro primeiro, v. 2. São Paulo: Nova Cultural, 1996.

MARINI, R. M. Dialética da Dependência. In: STÉDILE, João Pedro, TRASPADINI, Roberta (Org.). Ruy Mauro Marini: vida e obra. São Paulo: Expressão Popular, 2005.

NEVES, M. F. et al. Estratégias para a cana no Brasil: um negócio classe mundial. São Paulo: Altas, 2010.

PITTA, F. T. Modernização retardatária e agroindústria sucroalcooleira paulista: o Proálcool como reprodução fictícia do capital em crise. 2011. 184p. Dissertação (Mestrado em) - FFLCH, Universidade de São Paulo, São Paulo, 2011.

REDE SOCIAL DE JUSTIÇA E DIREITOS HUMANOS E COMISSÃO PASTORAL DA TERRA. Os impactos da produção de cana no cerrado e Amazônia. 2008. Disponível em: <http://www.social.org. br/cartilhaimpactoscana.pdf>. Acesso em: 27 jul. 2012. 
REDE SOCIAL DE JUSTIÇA E DIREITOS HUMANOS E COMISSÃO PASTORAL DA TERRA. Monopólio da produção de etanol no Brasil e a fusão da COSAN e da SHELL. 2011. Disponível em: <http://www. social.org.br/revistacosanshel.pdf>. Acesso em: 27 jun. 2012.

TRASPADINI, R. et al. (Org.). Ruy Mauro Marini: vida e obra. São Paulo: Expressão Popular, 2005. 304p.

SANT'ANA, R. S. Trabalho bruto no canavial: questão agrária, assistência social e serviço social. São Paulo: Cortez, 2012.

SANTOS, J. C. Dos canaviais à "etnolatria": o (re)ordenamento territorial do capital e do trabalho no setor sucroalcooleiro da Microrregião Geográfica de Presidente Prudente - SP. Uberlândia: Programa de Pós-Graduação em Geografia da Universidade Federal de Uberlândia, 2009.

SILVA, M. A. M. Errantes do fim do século. São Paulo: Fundação Editora da UNESP, 1999.

SILVA, M. A. O trabalho oculto nos canaviais paulistas. Revista perspectiva, São Paulo, v. 39, p. 11-46, 2011.

SILVA, M. A. A face oculta do trabalho: migrantes nas usinas canavieiras de São Paulo. Revista latinoamericana de estudios Del trabajo (RELET), ano 10, n. 17, p. 31-54, 2005.

STEDILE, J. P. A Questão Agrária no Brasil: 1500-1960. São Paulo: Expressão Popular, 2005.

STEDILE, J. P. Reflexões sobre as tendências do capital na agricultura e os desafios do Movimento Camponês da América Latina. In: Coletânea de textos para o curso de teoria latino-americana. UFJF, 2010.

SZMRECSÁNYI, T. et al. O desenvolvimento da agroindústria canavieira do Brasil desde a II Guerra Mundial. Revista de Estudos Avançados, São Paulo, v. 11, p. 59-79, jan./abr., 1991. Disponível em: <http://www.scielo.br/pdf/ea/v5n11/v5n11a06.pdf>. Acesso em: 01 fev. 2013. 